\title{
63
}

\section{An Industry Response to Comprehensive Enterprise Information Systems Management}

Bill WARNER, IBM, U.S.A.

Hear Bill Warner's perspective on the systems management challenges our customers are trying to overcome; and the corresponding actions that are required by vendors who desire success in the systems management business.

Today's systems management industry is changing fast and vendors must respond as fast to the variety of needs which span the enterprise of customers large and small. This poses a tremendous challenge both for the end user and the vendors; a challenge which can be overcomed with the right plan and strategic focus on the problems our customers are trying to solve -- a focus which begins with the customers business processes and not the information technology used to achieve their success.

Bill Warner will discuss the IBM response to simplifying the management process, the openness required for technology independence, and the plan for delivering strategic new functions in the future. 